\title{
A EDUCAÇÃO FÍSICA NO TERCEIRO GRAU: CONTEXTO ATUAL E PERSPECTIVAS
}

\author{
HEBER EUSTÁQUIO DE PAULA* E ELIENE LOPES FARIA**
}

\section{RESUMO}

O presente artigo versa sobre a questão da Educação Física no terceiro grau em face da Lei de Diretrizes e Bases da Educação Nacional, discutindo a sua inserção na Universidade, seus desdobramentos em diferentes contextos institucionais e apresentando algumas reflexões e perspectivas. PALAVRAS-CHAVE: Educação física no terceiro grau.

\section{INTRODUÇÃO}

$\mathrm{O}$ novo panorama da educação brasileira, apresentado a partir da aprovação da Lei de Diretrizes e Bases da Educação Nacional, em 20 de dezembro de 1996, estabelece aos trabalhadores na educação em todo o País um desafio instigante: como conceber efetivamente construir a educação, dando a ela o destaque e o tratamento políticopedagógico sintonizado com as necessidades de formação do educando em diferentes etapas da sua escolarização, preparando-o para o exercício de sua cidadania no sentido da construção de uma sociedade mais humanizada.

Nós, professores de Educação Física em diferentes níveis, devemos, então, nos associar ao esforço do conjunto dos profissionais da educação e nos propor à difícil e constante tarefa de sempre estar refletindo nossa prática social, criticando o contexto no qual estamos inseridos e, ainda, conhecendo esse contexto, para agir no sentido da transformação da sociedade.

Parece-nos muito importante refletir, neste momento em que se apresenta diante de nós um novo contexto sobre a nossa própria história, sobre o que temos feito em nossos campos de atuação e encontrar nesse novo panorama os elementos para a superaçâo dos conflitos e dos estrangulamentos que limitam a nossa prática educativa.

Nessa tarefa é fundamental pensar a Educação Física no terceiro grau, seu contexto passado, atual e suas perspectivas, buscando superar o seu cheiro de mofo e pólvora, arejando-a com novos entendimentos e propostas de inserção no seio da Universidade e, sobretudo, associando-a ao esforço no sentido de uma educação sempre maior.

* Professor do Departamento de Educação Física da Universidade Feder;. de Ouro Preto. Mestre em Educação Física pela Universidade Federal de Minas Gerais.

* Professora do Departamento de Educação Física da Universidade Federal de Ouro Preto. Mestranda em Educação na Faculdade de Educação da Universidade Federal de Minas Gerais. 


\section{A LDB EM QUESTÃO}

Com a aprovação da nova Lei de Diretrizes e Bases da Educação Nacional, muita coisa mudou na estrutura e no funcionamento do ensino do País. Uma importante característica desta nova Lei é o seu caráter flexibilizador, que possibilita às instituições de ensino, no exercício de sua autonomia, construir, dentre outras coisas, seu projeto políticopedagógico.

Um outro aspecto da Lei é a centralização garantida pelos siste-mas de avaliação, que - contraditoriamente ao caráter anterior - restringe o potencial criador das escolas e universidades, quando estas passam a ser avaliadas externamente, com critérios que tendem à homogeneização. No mesmo sentido, os 'famosos' Parâmetros Curriculares Nacionais acabam por dificultar que as culturas locais sejam inseridas e valorizadas no currículo escolar.

A Educação Física, no contexto da LDB, passa a ser 'interpreta-da' como uma disciplina - não mais uma atividade como previa o decreto 69.450/71 ${ }^{1}$-, que no seu Artigo 26, parágrafo 3. ${ }^{\circ}$, estabelece: “A educção física, integrada à proposta pedagógica da escola, é componente curricular da Educação Básica, ajustando-se às faixas etárias e às condi-ções da população escolar, sendo facultativa nos cursos noturnos”.

Se, por um lado, é possível considerar um avanço a sua nova inserção - como uma disciplina - no contexto escolar, por outro lado, seu estado de menoridade na hierarquia dos saberes escolares parece estar implícito em uma Lei que detalha sua inserção, propondo-lhe que se ajuste à proposta pedagógica da escola, o que não acontece, no texto da LDB, com as demais disciplinas.

Outro aspecto muito claro da Lei é a facultatividade da Educação Física nos cursos noturnos e a inexistência de uma referência ao ensino superior, o que, segundo Souza e Vago (1997), se trata de um processo de exclusão iminente. Isso acaba por encerrar uma imposição que legalizou a inserção obrigatória da Educação Física no Ensino Superior, promovida pelo Regime Militar no período de repressão, como forma de conter o envolvimento político e as mobilizações do estudante universitá-rio nas questões e problemas do País. ${ }^{2}$

Atualmente, o que se tem como referência para embasar as discussões da delicada posição da Educação Física no ensino superior é o Parecer n. 376/97, do Conselho Nacional de Educação, esclarecendo que "a sua oferta passa a ser facultativa para o ensino superior e decorre de proposta institucional de ensino e não de norma oriunda de órgão superior.” Desta forma, a Educação Física no ensino superior passa a ser prerrogativa dos processos decisórios de cada instituição de ensino no exercício de sua autonomia.

\section{DA OBRIGATORIEDADE DA EDUCAÇÃO FÍSICA NO ENSINO SUPERIOR}

Uma questão que vem, no decorrer dos anos, sendo alvo de grandes polêmicas é o caráter obrigatório da Educação Física no ensino superior.

Baseando-se em críticas que condenam a forma como esta foi inserida e como tem sido ministrada a Educação Física no ensino superior no decorrer dos anos, muitos advogam pela extinção de sua obrigatoriedade. Outros, no entanto, consideram a 
obrigatoriedade como um fator positivo, tendo como argumentação desde uma pedagogia crítica comprometida e de mérito acadêmico até interesses puramente corporativistas com o objetivo reducionista de resguardar o espaço de atuação do profissional.

Estudiosos da legislação que rege a Educação Física no País e de sua história advogam que sua obrigatoriedade no ensino superior já deveria ter sido extinta, visto que se trata, desde sua implantação, de um exercício de autoritarismo introduzi-la neste contexto.'

É muito bom saber que a obrigatoriedade como princípio não se justifica mais no atual contexto, mas é preciso que discutamos a obrigatoriedade inserida no contexto curricular de cada curso, em que há um rol de disciplinas obrigatórias.

Esse novo panorama nos impõe uma necessidade de constante busca da legitimidade da Educação Física no contexto universitário, o que já vem sendo construído, antes mesmo da aprovação da LDB, em algumas universidades do País. Essa deverá ser a meta dos grupos de trabalho (professores de Educação Física) envolvidos com a questão que ainda estão indefinidos neste novo cenário.

O movimento histórico de discussão acerca da Educação Física no $3^{\circ}$ grau (seminários, encontros e debates) parece, já há muito, indicar para a não-obrigatoriedade. No entanto, os documentos produzidos nestes eventos, que questionam a obrigatoriedade enquanto princípio, acabam sempre por acatá-la como forma de existência neste contexto, em função das políticas e tensões vividas no meio universitário. Acreditam que a obrigatoriedade é a forma mais segura de garantir o direito ao acesso à cultura corporal na universidade, embora esse discurso, em muitos casos, não tenha sido efetivado com programas de ensino de Educação Física no terceiro grau dignos desse nome.

Estas posturas parecem estar respaldadas por algumas preocupações :

1. Uma preocupação com o esvaziamento do setor, com uma possível retaliação do grupo de professores.

2. O decréscimo do número de alunos e aulas.

3. Uma preocupação com a superação de propostas pedagógicas já implantadas por uma Educação Física com caracterização de treina-mento e não de educação, que se limita como direito de uma minoria, ou, ainda, como fazer nos finais de semana.

Além de todas estas questões levantadas, consideramos importante que a Educação Física no $3 .^{\circ}$ grau não seja pensada de forma desconectada da realidade e do contexto de cada universidade. Isto significa, no entanto, que a instituição deverá estudar como a Educação Física participa de seu projeto de formação dos indivíduos (projeto políticopedagógico), oferecendo condições para que ela possa ser oferecida, caso o exercício de sua autonomia assim decida.

Cremos que a obrigatoriedade imposta pelo Decreto n. 69.450/71, já revogado, devesse ser superada e que nós, profissionais da área, almejássemos uma legitimidade com base nas necessidades e nos interesses de cada comunidade universitária, na qual o professor de Educação Física é um importante ator social.

Dessa forma, é preciso ainda que consideremos a questão dos argumentos, pois, pautada no argumento da força (baseado em leis), a Educação Física, principalmente no $3^{\circ}$ grau, tem muito mais se imposto como prática obrigatória do que como conhecimento e vivência necessária a cada sujeito. Isto demonstra a sua fragilidade e sua falta de identidade. Segundo Bracth (1991), "legitimar a Educação Física significa, então, apresentar argumentos plausíveis para sua permanência ou inclusão no currículo escolar, apelando exclusivamente para a força dos argumentos, declinando o argumento da força 
(...). A legitimação de uma matéria se dá em função do papel que determinada época lhe atribui."

Para essa legitimação é importante que não haja uma exclusão sumária da Educação Física, provocada por uma aplicação automática da Lei e sim que a autonomia proporcione uma relação dialógica entre os sujeitos, para deliberar sobre a questão.

Assim, é imprescindível, no trato da questão da obrigatoriedade da Educação Física no $3^{\circ}$ grau, estarmos atentos a alguns questionamentos que poderão nortear nossas ações, tais como: Que Educação Física queremos no ensino superior? Quais as suas possíveis contribuições neste nível de escolarização? A Educação Física depende realmente da obrigatoriedade para existir neste contexto? Qual o significado da obrigatoriedade e da nãoobrigatoriedade da Educação Física neste contexto? Como pensar a Educação Física não obrigatória na Universidade contribuindo para a formação dos sujeitos? Qual projeto político-pedagógico adotar diante da perspectiva da não-obrigatoriedade da Educação Física?

Poderíamos aqui enumerar ainda muitas outras questões, no entanto, acreditamos que as respostas podem variar de acordo com os sujeitos e os contextos. Para tanto, é importante o envolvimento dessa área - que não se limita aos professores atuantes no terceiro grau - para que consigamos avançar na construção da Educação Física que queremos.

Quanto ao fato das inúmeras contribuições possíveis e do compro-misso político pedagógico que vem sendo construído no campo de atua-ção da Educação Física no $3^{\circ}$ grau, acreditamos serem todos estes avanços consideráveis e fundamentais, pois a Universidade se faz dos corpos em movimento que vivenciam sua realidade, com intencionalida-des e subjetividades diferenciadas. Por isso, consideramos importante reconhecê-los dentro deste contexto. A Educação Física é essencial neste processo quando assumida com compromisso -, visto ser uma discipli-na que trata da corporeidade dos sujeitos no âmbito da Universidade, embora nem sempre isso aconteça.

É importante também perceber que estes corpos têm o direito à Educação Física, não mais como obrigação insignificante, mas como espaço legítimo para se aprender cada vez mais a viver e sentir-se corpo, garantido pela própria instituição, na implementação de seu projeto. Isso não se faz por meio de imposições inflexíveis e sim através de respeito à história de movimento de cada sujeito e de respeito às possíveis contribuições da Educação Física neste processo de humanização do homem.

A Educação Física tem, com certeza, múltiplos caminhos a seguir - que precisam ser traçados - no contexto universitário, o que vai depen-der dos diversos atores sociais envolvidos neste cenário. No entanto, é preciso que consigamos superar o paradigma da obrigatoriedade a qualquer custo na busca de novos horizontes, onde a Educação Física se constitua como direito do estudante à cultura corporal na Universidade.

Atentos às novas perspectivas da Educação Física e comprometi-dos com as mudanças sociais que desejamos, precisaremos nos respaldar em uma Educação Física que seja formadora de sujeitos críticos e partici-pantes da sociedade, contribuindo para o processo educacional de forma conscientizadora a fim de que possa se projetar no fortalecimento da sociedade e da própria Universidade. 


\section{EDUCAÇÃO FÍSICA NO TERCEIRO GRAU APONTANDO NOVOS CAMINHOS}

A “prática esportiva” ou Educação Física no terceiro grau tem, ao longo de sua existência, assumido diferentes sentidos e significados. Esses significados não são dados e nem mesmo são inerentes ao que se convencionou chamar de "prática esportiva", sendo, portanto, construídos pelos atores sociais presentes na cena universitária a cada momento, considerando o contexto, os meios, os recursos humanos, as necessidades e políticas institucionais, bem como os direcionamentos políticos e ideológicos presentes na legislação e na atuação docente.

O significado das práticas sociais é construído e expresso pelo desejo, pela intencionalidade das ações e pela capacidade de articulação das pessoas presentes nos diferentes contextos onde essas ações são implementadas.

O significado e o sentido histórico da "prática esportiva", quando de sua implantação no fim dos anos 70 e início dos anos 80, por uma simples consulta e análise da legislação, se mostram claramente excludentes, competitivistas, biologizantes e disciplinadores. Esse sentido histórico, como sabemos, foi implementado com a clara intenção de se amainar o desejo, encobrir e eliminar a intencionalidade e esfacelar a capacidade de articulação das pessoas, como parte de um projeto do regime militar de repressão no meio universitário.

Sob essa determinação, surgem nas universidades, em diferentes momentos, de modo mais ou menos afinado ou até mesmo em discordância com a proposta da legislação, grupos de profissionais que se encarregaram de desenvolver a prática esportiva ou Educação Física no terceiro grau, edificando sentidos e significados diferenciados.

A partir desse quadro inicial, construíram-se, do momento da sua implantação até os nossos dias, diferentes propostas para a chamada "prática esportiva", variando desde o mais rigoroso cumprimento da lei - alheio aos interesses de uma educação maior, incapaz de responder aos imperativos da formação do universitário - até propostas inovadoras, críticas e superadoras do propósito inicial da legislação, apontando na direção da Educação Física no terceiro grau como parte de um projeto maior de Educação Superior.

Assim, houve situações em que a prática esportiva sequer foi implantada, outras em que ela ocorreu e ocorre estritamente sob as normativas do Decreto-lei, e outras ainda em que grupos de professores transformaram seu sentido original, substituindo-o por um sentido reflexivo, democrático e superador.

O quadro atual da educação física na Universidade indica que, na maioria das instituições, não foi possível a construção de sentidos afinados com os propósitos da Educação Superior, mas temos também casos em que, através de uma mediação competente, os significados preexistentes foram absorvidos, transformados e desconstruídos para se edificarem novos sentidos para a prática esportiva.

Se no quadro anterior, o de obrigatoriedade, muitas instituições não foram capazes de refletir e dar novos sentidos à prática esportiva, hoje, retirado o manto da obrigatoriedade legal e substituído pela autonomia das instituições universitárias, a sobrevivência das experiências positivas, mesmo as mais avançadas, exigiria esforço, contextualização, competência política e pedagógica.

Essa tarefa demanda tempo, esforço e uma análise das possibilidades locais para a Educação Física no terceiro grau que considere, ao nosso ver, pelo menos quatro planos centrais: 
- $\quad$ plano da formação do universitário;

- $\quad$ plano da formação do professor de Educação Física;

- $\quad$ plano da construção do lazer na Universidade;

- planos político, administrativo e institucional.

No plano da formação do universitário, é necessário refletir sobre o papel e a necessidade da Educação Física no terceiro grau como elemento formador. Se ela faz parte de um projeto maior de educação, é dever das instituições garantir o direito de o aluno acessar os conteúdos e as metodologias de ensino propostas. Cabe a estas instituições oportunizar o conhecimento de um espaço construído com esforços e de fundamental importância na concepção de Educação Superior que compartilhamos, não se reduzindo à mera reprodução de técnicas e ao acesso ao conhecimento científico, mas concebendo a sua tarefa de formar e educar o homem na sua plenitude.

Nas instituições onde existem escolas de Educação Física, pode-ríamos pensar na integração e na vivência necessária para a formação do futuro profissional sendo desenvolvida de modo a trazer a necessária reflexão sobre as questões do esporte, do lazer e da Educação Física na Universidade e de suas possibilidades nesse contexto e em contextos similares. Para isso é fundamental que os docentes façam essa aproximação pensando diferentes formas de conceber a "prática esportiva” na Universidade e seu possível papel na formação dos profissionais de Educação Física.

No plano do lazer na Universidade, parece-nos bastante possível que, integrando-se a outras áreas do conhecimento instaladas nas instituições, a Educação Física no terceiro grau ajude a pensar uma política universitária de lazer adequada às necessidades institucionais, articulando recursos, meios e pessoas, a fim de produzir um movimento em que seja possível o lazer como elemento articulador da "vida universitária", dinamizando-a e potenciando-a em todos os seus aspectos.

Nos planos político, administrativo e institucional, é possível o fortalecimento das unidades, institutos, ou escolas de Educação Física através do estabelecimento de interfaces entre essas e o conjunto da Universidade. Os programas de ensino (Educação Física no terceiro grau) e de extensão (políticas culturais) podem viabilizar esse fortalecimento na medida em que, fazendo-se presente no contexto universitário e participando da implementação de políticas de cultura e lazer, proponham uma prática reflexiva no campo da educação universitária. Assim, as escolas de Educação Física poderiam assumir um importante papel na vida da universidade, influenciando diversas ações na comunidade universitária.

Pensar esta inserção no seio da Universidade para a Educação Física não é tarefa fácil. É preciso compreender as necessidades institucionais, apreender os diferentes contextos de atuação, entendendo as suas potencialidades e limitações, além de ter clareza das especificidades da Educação Física no terceiro grau, construindo e efetivando o seu potencial formador, articulador e político. 
This paper presents ideas related to the physical education at university, its inclusion in tbc context of the new Law, presenting some considerations and perspectives.

KEY-WORDS: Physical education at university.

\section{REFERÊNCIAS BIBLIOGRÁFICAS}

BRACHT, Valter. Educação Física e aprendizagem social. Porto Alegre: Magister, 1992.

BRASIL. Congresso Nacional. Lei de Diretrizes e Bases da Educação Nacional. Brasília. 20 dez.1996.

CASTELLANI FILHO, Lino. Educação Física no Brasil: a história que não se conta. Campinas: Papirus, 1998.

.Os impactos da reforma educacional na Educação Física brasileira. In: X Congresso Brasileiro de Ciências do Esporte. Anais... Goiânia: UFG, set., 1997, p. 20-35.

COLÉGIO BRASILEIRO DE CIÊNCIAS DO ESPORTE (Org.). Educação física escolar frente à LDB e PCNs: profissionais analisam renovações, modismos e interesses. Ijuí. SEDIGRAF, 1997. $141 \mathrm{p}$.

SOUSA E VAGO. A nova LDB: repercussões no ensino da Educação Física. Presença Pedagógica. Belo Horizonte: v. 3, n. 16, jul./ago. 1997. p. 19-29 